\title{
Evaluation of Clinical and Laboratory Findings of Children with Vitamin B12 Deficiency
}

\author{
Erhan Aygün ${ }^{*}$, Özden Aksu Sayman², Sena Yiğitoğlu², Sevgi Sipahioğlu², Emine Yurdakul \\ Ertürk $^{2}$, Abdullah Eren Yiğitoğlu², Gülbahar Kurt Bayır ${ }^{2}$, Ecem İpek Altınok ${ }^{2}$ and Mediha Şa- \\ hin $^{2}$
}

${ }^{1}$ Division of Neonatology, Department of Pediatrics, Ordu University Training and Research Hospital, Turkey

${ }^{2}$ Department of Pediatrics, Ordu University Training and Research Hospital, Turkey

*Corresponding author: Erhan Aygün, MD, Division of Neonatology, Department of Pediatrics 52200 Ordu University Training and Research Hospital, 52200 Ordu, Turkey.

To Cite This Article: Erhan Aygün, Özden Aksu Sayman, Sena Yiğitoğlu, Sevgi Sipahioğlu, Evaluation of Clinical and Laboratory Findings of Children with Vitamin B12 Deficiency. Am J Biomed Sci \& Res. 2021 - 11(6). AJBSR.MS.ID.001698. DOI: 10.34297/AJBSR.2021.11.001698.

Received: 眥 February 01, 2021; Published: 制 February 12, 2021

\begin{abstract}
Objective: Vitamin B12 deficiency causes significant neurological, hematological and gastrointestinal system problems in children. Many systemic problems can be prevented with early recognition and treatment of Vitamin B12 deficiency, which is an important public health problem in all over the world. We aimed to evaluate children who applied to pediatric health and diseases outpatient clinics and were found to have vitamin B12 deficiency.

Materials and Methods: Children aged 0-18 years who were admitted to the Education and Research Hospital Pediatrics outpatient clinics for any reason and were found to have vitamin B12 deficiency were evaluated retrospectively. Age, gender, admission complaints, serum vitamin B12 levels, leukocyte in complete blood count, hemoglobin (Hb), mean erythrocyte volume (MCV), platelet values, ferritin, thyroid function tests (TSH and fT4) were evaluated.

Findings: A total of 137 (60.6\%) of the 226 cases that were included in our study were girls, and 89 (39.4\%) were boys. The mean age of the cases was 10 \pm 7.6 years. Macrocytosis was not observed in cases with anemia. Iron deficiency was present together with Vitamin B12 deficiency in $26(11 \%)$ of the cases. Iron deficiency was detected together with Vitamin B12 deficiency in 18 (8\%) of the cases diagnosed with anemia. In our study, anemia was found in $18.2 \%$ of the cases, neutropenia in $8.4 \%$, and thrombocytopenia in $0.8 \%$. The most common complaints were fatigue and loss of appetite (24.8\%), growth retardation (short stature, inability to gain weight) (13.7\%), chest pain, syncope and palpitations (8.4\%).
\end{abstract}

Results: We think that it would be appropriate to evaluate vitamin B12 levels in children with undiagnosed neurological, respiratory, gastrointestinal or cardiac complaints who were admitted to pediatric outpatient clinics.

Keywords: Vitamin B12 deficiency, Child health

\section{Introduction}

Vitamin B12 is a water-soluble vitamin and is obtained from animal products, such as red meat, dairy products, and eggs. The intrinsic factor is a glycoprotein that is produced by parietal cells in the stomach and is essential for the absorption of Vitamin B12 in the terminal ileum. After Vitamin B12 is absorbed, it is used as a cofactor for the enzymes, which play roles in the synthesis of the DNA, fatty acids, and myelin. Inadequate intake of it with diet, intestinal absorption disorders, and autoimmune metabolic diseases cause Vitamin B12 deficiency [1].
Vitamin B12 deficiency causes significant neurological diseases (convulsion, restlessness, hypotonia, mental and motor retardation, language development problems, paralysis, ataxia, and depression), hematological diseases (anemia, neutropenia, and thrombocytopenia), and gastrointestinal system diseases (loss of appetite, stomatitis, glossitis) in children [1-7].

Many systemic problems can be prevented with early recognition and treatment of Vitamin B12 deficiency, which is an important public health problem in our country. 
The purpose of the present study was to evaluate children between 0-18 years of age who admitted to children's health and diseases clinics for various reasons, and who have Vitamin B12 deficiency.

\section{Material and Method}

Patients admitting to Ordu University, Educational Research Hospital, Children's Health and Diseases Clinics for any reason, and who were detected to have Vitamin B12 deficiency were evaluated retrospectively in the present study.

Serum Vitamin B12 levels below $200 \mathrm{pg} / \mathrm{mL}$ were considered to be low values (1). Patients between the ages of 0-18 who admitted between the dates January 2020 and November 2020, and who had Vitamin B12 deficiency were examined retrospectively.

Serum Vitamin B12 levels were measured by using Electrochemiluminescent Immunoassay (ECLIA) Method with Roche Cobas e-801 Device.

The age, gender, admission complaints, serum vitamin B12 values, leukocyte, hemoglobin ( $\mathrm{Hb})$, Mean Erythrocyte Volume (MCV), platelet values, ferritin, and thyroid function test results (TSH and sT4) were evaluated in full blood count.

a. Blood values were examined as Full Blood Count, serum iron, and ferritin in Ordu University, Educational Research Hospital, Biochemistry Department Laboratory.

Leukocyte, hemoglobin, MCV, platelet, serum iron, iron-binding capacity, and ferritin values were examined according to age and gender [5).

b. Normal leukocyte values were $9.100-34.000 / \mathrm{mm} 3$ for 0-1 month, $6.000-14.000 / \mathrm{mm} 3$ for 1 month-23 months, 4.000 $12.000 / \mathrm{mm} 3$ for $2-9$ years of age, and $4.000-12.000 / \mathrm{mm} 3$ for 9-18 years of age. Low leukocyte values according to age was considered as leucopenia, and high values were considered as leukocytosis.

c. Normal hemoglobin values were taken as $15-24 \mathrm{~g} / \mathrm{dL}$ for 0-1-month, 10.5-16.1 g/dL for 1 month-23 months, 11.5-14.5 $\mathrm{g} / \mathrm{dL}$ for 2-9 years, $12-15 \mathrm{~g} / \mathrm{dL}$ for girls who are aged $10-18$, and 12.5-16.1 g/dL for boys who are aged 10-18. Low hemoglobin values according to age was considered as anemia.

d. MCV normal values were taken as 99-115fL for 0-1 month, 72-88 fL for 1 month-23 month, 76-90 fL for 2-9 years, 78-95 fL for 10-18 years. Low MCV value according to age was evaluated as microcytosis, and high MCV value was evaluated as macrocytosis.

e. Normal platelet values were taken as $150.000-400.000 /$ $\mathrm{mm} 3$ for all age groups. Low platelet value was evaluated as thrombocytopenia, and high platelet value was evaluated as thrombocytosis. f. Normal ferritin values were taken as 0-400 $\mathrm{ng} / \mathrm{mL}$ for $0-6$ weeks, $10-95 \mathrm{ng} / \mathrm{mL}$ for 7 weeks-1 year, $10-60 \mathrm{ng} / \mathrm{mL}$ for $1-9$ years, 10-70 ng/mL for girls for 10-18 years, and 10-300 ng/ $\mathrm{mL}$ for boys [5].

g. TSH was taken as $0.5-6.5 \mathrm{mU} / \mathrm{L}$ for $0-1$ month, $0.5-6.0 \mathrm{mU} /$ L for 1-6 months, $0.5-4.5 \mathrm{mU} / \mathrm{L}$ for 6 months-18 years of age.

h. $\quad$ ST4 was taken as $0.90-2.20 \mathrm{ng} / \mathrm{dL}$ for $0-1$ month, and $0.7-$ $2.00 \mathrm{ng} / \mathrm{dL}$ for 1 month-18 years of age.

Approval was obtained from Ordu University Training and Research Hospital Clinical Research Ethics Committee (Decision no: 2020/212).

\section{Statistical Analyses}

Statistical analyses were made with IBM SPSS 21 (Statistical Package for the Social Sciences) Package Program. The categorical data for descriptive analyses were given as frequencies (n) and percentages (\%), and continuous data were given as mean, standard deviation, median, and 25 and 75 percentile values. The suitability of the variables to normal distribution was examined with visual (histogram) and analytical methods (Shapiro-Wilk Test). The Chi-Square Test was used in the analysis of categorical variables, and the Mann-Whitney U-Test was used when the distribution of normality was not met in comparisons of continuous variables of two independent groups. Situations where the $\mathrm{p}$ value was below 0.05 were taken as being statistically significant.

\section{Results}

A total of 137 (60.6\%) of the 226 cases that were included in our study were girls, and 89 (39.4\%) were boys. The mean age of the cases was $10 \pm 7.6$. The most common admission complaint was weakness and loss of appetite, and it was determined that Vitamin B12 deficiency was detected during routine check-ups in most cases. The admission complaints of the cases participating in the study are given in Table 1.

A total of 165 (73\%) did not have any pathological physical examination findings at the time of diagnosis in 226 patients who participated in the study, and the most common pathological physical examination finding were recorded as fading and hypotonia in the skin and mucosa, and growth and development deficiency in the remaining 61 patients (27\%). Other pathological findings were detected as oral aphtha, functional murmur, acanthosis nigricans, ataxia, and growth in the lymph node. Among the cases participating in the study, 2 cases were followed-up with Diabetes Mellitus, 1 case due to West Syndrome, and 1 case due to hypothyroidism.

There were TSH elevation and low sT4 levels in 1 case that was followed-up due to hypothyroidism. Aside from this case, the sT4 levels of all the cases participating in the study were determined at normal limits; and TSH value was above normal limits in only 9 cases. Laboratory values of the cases participating in the study 
are given in Table 2. It is already known that B12 deficiency can lead to low results in other blood series besides anemia. When the laboratory values of the cases who participated in the study were evaluated according to age groups, anemia was detected in $41(18.2 \%)$, and bicytopenia was detected in 4 (1.7\%) patients. There were no pancytopenia cases. Although it is also known that B12 deficiency generally causes macrocytary anemia, MCV elevation was detected in only 2 cases according to age group, and macrocytosis was not detected in patients with anemia (Table 3).

Table 1: Admission complaints of the cases participating in the study.

\begin{tabular}{|c|c|c|}
\hline & $\mathbf{n}$ & $\mathbf{2}$ \\
\hline Weakness, lack of appetite & 56 & 24,8 \\
\hline Overweight & 18 & 8 \\
\hline Jaundice & 6 & 2,7 \\
\hline Chest pain, syncope, palpitation & 19 & 8,4 \\
\hline Headache, Dizziness & 17 & 7,6 \\
\hline GIS problems (diarrhea, constipation, stomachache) & 13 & 5,6 \\
\hline Growth deficiency (short status, failure to thrive) & 31 & 13,8 \\
\hline Amnesia & 5 & 2,2 \\
\hline Tremor & 3 & 1,3 \\
\hline Inability to keep head straight & 3 & 1,3 \\
\hline Complaint not known & 55 & 24,3 \\
\hline
\end{tabular}

Table 2: Laboratory Values of the Cases Participating in the Study.

\begin{tabular}{|c|c|c|}
\hline & Mean \pm SD & Median $(25 p-75 p)$ \\
\hline B12 (ng/L) & $164,1 \pm 26,9$ & $168,4(147,7-186)$ \\
\hline WBC $(10 * 3 /$ UL) & $7,6 \pm 2,5$ & $7,1(6,1-8,9)$ \\
\hline NEU $(10 * 3 /$ UL) & $3,4 \pm 1,6$ & $3,2(2,4-4,1)$ \\
\hline HBG (g/dl) & $12,7 \pm 1,7$ & $12,9(11,9-13,7)$ \\
\hline MCV (fl) & $80,9 \pm 7,4$ & $81,5(77,5-86)$ \\
\hline MCH (pg) & $27,2 \pm 3,5$ & $27,4(25,8-29,1)$ \\
\hline HCT (\%) & $37,5 \pm 4,2$ & $37,9(35,1-40,1)$ \\
\hline PLT (10*3/UL) & $302 \pm 81$ & $284(259-341)$ \\
\hline LYMPHOCYTE (10*3/UL) & $3,3 \pm 1,9$ & $2,7(2,1-3,7)$ \\
\hline TSH (mU/L) & $2,6 \pm 2,1$ & $2,2(1,5-3,3)$ \\
\hline ST4 (ng/dL) & $0,92 \pm 0,5$ & $1,1(0,8-1,2)$ \\
\hline FERRITIN ( $\mu$ /L) & $37,9 \pm 33,4$ & $30,6(16,7-51,2)$ \\
\hline
\end{tabular}

Table 3: Examining the Laboratory Values of the Participants of the Study according to the Normal Limits of Age Groups.

\begin{tabular}{|c|c|c|}
\hline & $\mathbf{n}$ & $\mathbf{\%}$ \\
\hline WBC & & \\
\hline Leukocytosis & 1 & 0,6 \\
\hline Within normal limits & 214 & 94,6 \\
\hline Leukopenia & 11 & 4,8 \\
\hline Neutrophilia & & \\
\hline Neutrophilia & 0 & \\
\hline Within normal limits & 207 & 91,6 \\
\hline
\end{tabular}

Iron deficiency was present together with Vitamin B12 deficiency in 26 (11\%) of the cases. Iron deficiency was detected together with Vitamin B12 deficiency in 18 (8\%) of the cases diagnosed with anemia. The percentage of microcytic anemia was significantly higher and hemoglobin values were significantly lower in anemia cases that had iron and Vitamin B12 deficiency together compared to those with only B12 deficiency $(\mathrm{p}<0.05)$. No significant differences were detected in comparisons with age and gender (Table 4). 


\begin{tabular}{|c|c|c|}
\hline Neutropenia & 19 & 8,4 \\
\hline PLT & 2 & 0,8 \\
\hline Thrombocytopenia & 223 & 99,2 \\
\hline Within normal limits & 0 & 18,2 \\
\hline Thrombocytosis & & 81,8 \\
\hline HGB & 41 & \\
\hline Anemia & 185 & 87,2 \\
\hline Within normal limits & & 12 \\
\hline MCV & 27 & 0,8 \\
\hline Normocytic & 2 & \\
\hline Macrocytic & & \\
\hline Lymphocyte & 12 & \\
\hline Lymphopenia & 214 & \\
\hline Within normal limits & 0 & 94,7 \\
\hline Lymphocytosis & & \\
\hline
\end{tabular}

Table 4: Evaluation of Cases with Anemia.

\begin{tabular}{|c|c|c|c|}
\hline & B12 deficiency & B12 + Iron deficiency & $\mathbf{P}$ \\
\hline \multicolumn{4}{|c|}{ MCV n (\%) } \\
\hline Microcytic & 5 & 12 & \multirow{2}{*}{$0,004 *$} \\
\hline Normocytic & 18 & 6 & \\
\hline \multicolumn{4}{|c|}{ Gender n (\%) } \\
\hline Female & 16 & 13 & $0,56^{*}$ \\
\hline Male & 7 & 5 & \\
\hline Mean age \pm SD (median) & $10,7 \pm 6,6(11,5)$ & $9,3 \pm 6,9(14)$ & $0,71^{* *}$ \\
\hline Hemoglobin (mg/dl) & $11 \pm 1,2(11,5)$ & $9,7 \pm 1,8(10)$ & 0,01** \\
\hline \multicolumn{4}{|c|}{ *Chi-Square Test **Mann Whitney U-Test } \\
\hline
\end{tabular}

\section{Discussion}

Vitamin B12 deficiency is more common in developing countries. The prevalence varies between $3-40 \%$ in children in the world $[8,9]$.

Although it is known that Vitamin B12 deficiency causes macrocytary anemia, no macrocytosis was detected in patients with anemia in our study. Iron deficiency was detected together with Vitamin B12 deficiency in 18 (8\%) of the cases with anemia. The percentage of microcytic anemia was significantly higher and hemoglobin value was significantly lower in anemia cases that had iron and Vitamin B12 deficiency detected together than anemias with Vitamin B12 deficiency alone $(\mathrm{p}<0.05)$. MCV may be detected as low or normal in patients with iron deficiency together with Vitamin B12 deficiency. Iron deficiency anemia is common in our country. For this reason, the diagnostic interpretation of MCV may cause misevaluation of cases. It was reported in the literature that iron deficiency masks macrocytosis in macrocytary anemia $[10,11]$. The diagnosis of Vitamin B12 deficiency cannot be excluded when anemia and/or macrocytosis are not present [12]. In our study, $18.2 \%$ of cases had anemia, $8.4 \%$ had neutropenia, and $0.8 \%$ had thrombocytopenia. There are studies in the literature reporting that there were no significant differences when children with and without Vitamin B12 deficiency were compared in terms of leukocyte, neutrophil, hemoglobin, MCV and platelet values [13].

Despite Vitamin B12 deficiency in our cases, the parameters that were examined in full blood counts were mostly normal, which shows that hematological parameters alone cannot guide diagnostic evaluation [13].

The admission complaints of individuals with Vitamin B12 deficiency vary among age groups. Patients may be asymptomatic or may be diagnosed with significant life-threatening hematological and neurological diseases [4-6,9].

In the study Evim et al. the most common symptoms in children were weakness, growth deficiency, hematological symptoms (paleness, petechia, and ecchymosis), gastrointestinal and 
neurological symptoms, respectively. Again in the same study, it was also reported that neurological symptoms were more significant in patients who were under 2 years of age [14]. Studies were reported in the literature supporting more significant neurological symptoms at the first 2 years of age [15-17]. The most common complaint was reported as faintness in another study in which $82 \%$ of cases were under two years of age [18].

In the present study, the most common admission complains were weakness and loss of appetite (24.8\%), growth deficiency (short stature and inability to gain weight) (13.7\%), chest pain, syncope and palpitation (8.4\%).

Although the mechanism of neurological symptoms in Vitamin B12 deficiency is not known completely, delayed myelination, neurotrophic and neurotoxic cytokine and lactate accumulation in the brain cells were argued to be the causes [19].

When all these findings are evaluated together, Vitamin B12 deficiency shows itself with non-specific admission complaints, clinical findings, and laboratory data in childhood.

The retrospective design of the present study, the inability to access the anthropometric data and dietary status of the cases in detail were important limitations. Also, the lack of examining the most original and specific marker of Vitamin B12 deficiency with urine/serum methyl malonic acid level was not another limitation.

Wider prospective studies covering admission complaints, clinical findings and laboratory data according to age groups will ensure that Vitamin B12 deficiency is noticed earlier. In this way, preventable life-threatening problems can be prevented.

\section{Results}

1. Children with Vitamin B12 deficiency most often admitted with fatigue, loss of appetite, and growth deficiency.

2. Anemia was detected only in $18.2 \%$ of patients who had Vitamin B12 deficiency, and macrocytosis was not detected in patients with anemia.

3. Accompanied by iron deficiency, B12 Vitamin deficiency masks the development of macrocytosis.

4. We think that it will be appropriate to evaluate Vitamin B12 levels in children admitting to child health and diseases clinics with neurological, respiratory, gastrointestinal, or cardiological complaints that cannot be diagnosed.

\section{References}

1. Ankar A, Kumar A (2020) Vitamin B12 Deficiency. Treasure Island (FL): StatPearls.
2. Rasmussen SA, Fernhoff PM, Scanlon KS (2001) Vitamin B12 deficiency in children and adolescents. J Pediatr 138(1): 10-7.

3. Whiteheat VM, Rosenblatt DS, Cooper BA (2007) Megaloblastic Anemia. In. Nathan DG, Orkin SH. Nathan and oski's Hematology of Infancy and Chilhood. (7th Ed.), W.B. Saunders Co: Philadelphia. Pp. 469-501.

4. Serin HM, Arslan EA (2019) Neurological Symptoms of Vitamin B12 Deficiency: Analysis of Pediatric Patients. Acta Clin Croat 58(2): 295-302.

5. Kliegman RM, Geme JW (2020) Nelson Textbook of Pediatrics. 21th edition. Philadelphia.

6. Venkatramanan S,Armata IE,Strupp BJ,Finkelstein JL (2016) Vitamin B-12 and Cognition in Children. Adv Nutr 7(5): 879-888.

7. Mtvarelidze ZG, Kvezereli Kopadze AN, Kvezereli Kopadze MA (2009) Megaloblastic vitamin B12 deficiency anemia in childhood. Georgian Med News 170: 57-60.

8. Demir N, Koc A, Üstyol L, Peker E, Abuhandan M (2013) Clinical and neurological findings of severe vitamin B12 deficiency in infancy and importance of early diagnosis and treatment. J Paediatr Child Health 49(10): 820-824.

9. Karakurt N, Albayrak C, Yener N, Albayrak D (2019) Does Vitamin B12 Deficiency in Infants Cause Severe Clinical Symptoms Necessitating Intensive Care? J Pediatr Emerg Intensive Care Med 6: 134-139.

10. Oakley GP (1997) Let's increase folic acid fortification and include vitamin B-12. Am J Clin Nutr 65(6): 1889-1890.

11. Emen B, Öztürk YK, Eren MA, Özdemir E, Öztürk F, et al. (2013) A Retrospective Evaluation of the Relationship Between Etiology Factors and Laboratory Data in Patients with B12 Vitamin Deficiency.Tepecik Eğitim Hast Derg 23(1): 19-23.

12. Arslan EA (2020) Neurological Findings of Vitamin B12 Deficiency in Children: Analysis of 120 Patients. ACU Health Science Journal 11(1): 83-88.

13. Aydogdu A, Colak MA, Toprak B, Kose E, Ustuner F (2012) B12 vitamin level in children and its relationship with complete blood count parameters. Izmir Dr. Behçet Uz Hospital Journal of Pediatrics 2(2): 75-79.

14. Sezgin Evim M, Erdal Ş, Özdemir Ö, Baytan B, Güneș AM (2011) Longterm outcome in children with nutritional vitamin B12 deficiency. Turk J Haematol 28(4): 286-293.

15. Casella EB, Valente M, de Navarro JM, Kok F (2005) Vitamin B12 deficiency in infancy as a cause of developmental regression. Brain Dev 27(8): 592-594.

16. Weis R, Fogelman Y, Bennett M (2004) Severe B12 deficiency in an infant associated with a maternal deficiency and a strict vegetarian diet. J Padiatr Hematol Oncol 26(4): 270-271.

17. Zengin E, Sarper N, Caki Kiliç S (2009) Clinical manifestations of infants with nutritional vitamin B deficiency due to maternal dietary deficiency. Acta Paediatr 98(1): 98-102.

18. Taskesen M, Okur N, Katar S, Okur N, Soker M (2009) e-SPEN , the European e-Journal of Clinical Nutrition and Metabolism Nutritional megaloblastic anemia during childhood : Demographical , clinical and laboratory features of 134 patients from southeastern part of Turkey. E Spen Eur E J Clin Nutr Metab 4(3): e152-4.

19. Dror DK, Allen LH (2008) Effect of vitamin B12 deficiency on neurodevelopment in infants: current knowledge and possible mechanisms. Nutr Rev 66(5): 250-255. 